\title{
Peptostreptococcus anaerobius
}

National Cancer Institute

\section{Source}

National Cancer Institute. Peptostreptococcus anaerobius. NCI Thesaurus. Code C86645.

A species of obligately anaerobic, Gram-positive, coccobacillus shaped bacteria assigned to the phylum Firmicutes. This species is nonmotile, non-spore forming, catalase positive, indole, coagulase, and urease negative, produces gas from peptone-yeast-glucose medium, is moderately saccharolytic, but does not reduce nitrate, hydrolyze starch or esculin, produce propionate from lactate, or liquefy gelatin. P. anaerobius is commensal to human mucocutaneous surfaces, but can become pathogenic in other locations. 